Puede citar este artículo como:

Baydal Sala, Vicent y Soler Milla, Juan Leonardo. «Nuevas visiones sobre el desarrollo político europeo bajomedieval». Anales de la Universidad de Alicante. Historia Medieval, N. 19 (2015-2016): 33-40, DOI:10.14198/medieval.2015-2016.19.01

\title{
NUEVAS VISIONES SOBRE EL DESARROLLO POLÍTICO EUROPEO BAJOMEDIEVAL
}

\author{
Vicent Baydal Sala \\ Universitat Jaume I, Castelló de la Plana \\ Juan Leonardo Soler Milla \\ Universidad de Alicante
}

La publicación del libro The Making of Polities: Europe, 1300-1500 del profesor de Oxford John Watts, en el año 2009 -recientemente traducido al castellano-, supuso un brillante contrapunto y un certero complemento a las numerosas obras publicadas como resultado de los diversos programas de investigación sobre el origen de los Estados modernos, impulsados durante las décadas anteriores por el Centre National de la Recherche Scientifique y la European Science Foundation bajo el liderazgo del francés Jean-Philippe Genet, de La Sorbonne, y el belga Wim Blockmans, de Leiden ${ }^{1}$. Si bien estos últimos hacían énfasis en la importancia del alcance europeo del proceso de crecimiento de las estructuras estatales y de las instituciones centralizadas de gobierno a partir de la segunda mitad del siglo XIII como motor de las transformaciones políticas, el primero insistía en remarcar dicha generalización no

\footnotetext{
WATTS, J., The Making of Polities: Europe, 1300-1500, Cambridge, 2009; La formación de los sistemas políticos. Europa (1300-1500), Valencia, 2016. Por lo que respecta a los proyectos dirigidos por Genet y Blockmans, la producción resultante ha sido voluminosa, por ejemplo: GENET, J. P., L'État moderne: genèse. Bilans et perspectives, París, 1990; La genèse de l'État moderne: culture et société politique en Angleterre, París, 2003; BLOCKMANS, W. P. y GENET, J. P. (ed.), Visions sur le développement des états européens. Théories et historiographies de l'état moderne, Roma, 1993; BONNEY, R. (ed.), Economic Systems and State Finance, Oxford, 1995; REINHARD, W. (ed.), Power Elites and State Building, Oxford, 1996; COLEMAN, J. (ed.), The Individual in Political Theory and Practice, Oxford, 1996; BLICKLE, P. (ed.), Resistance, Representation and Community, Oxford, 1997; PADOA-SCHIOPPA, A. (ed.), Legislation and Justice, Oxford, 1997; ELLENIUS, A. (ed.), Iconography, Propaganda, and Legimitation, Oxford, 1998; CONTAMINE, P. (ed.), War and Competition between States, Oxford, 2000.
} 
solo aplicada a la figura del Estado central, sino al conjunto de estructuras de poder que se desarrollaron simultáneamente durante aquella época, también en muchos otros ámbitos, como el señorial, el eclesiástico, el municipal, el profesional, el interestamental, etc.

El crecimiento y multiplicación de los poderes en pugna habría sido el causante, en este sentido, de la enorme conflictividad documentada durante el período a todos los niveles, tanto de tipo militar como político, social y económico, que se fue generando de manera paralela a la progresiva legitimación de algunas de aquellas instituciones de poder emergentes y la creciente politización de la sociedad. En relación con ello, tanto el desarrollo institucional como los conflictos se habrían producido sobre la base de unas estructuras culturales comunes, que proporcionaron un lenguaje y unos valores compartidos por los diferentes actores protagonistas del proceso. En conjunto, la visión de Watts se revela como realmente integradora y global a la hora de explicar los cambios políticos producidos durante el período bajomedieval, por lo que resulta, como se indicaba, un complemento y un contraste necesarios a la ingente obra estimulada por Genet y Blockmans. Tanto es así que, en cierta manera, ambas perspectivas han acabado encontrándose en una de las obras de historia política comparativa más ambiciosas y completas de los últimos tiempos, Government and Political Life in England and France, c. 1300-c. 1500, que muestra los cambios producidos en las cortes, los ejércitos, la administración, las finanzas, la justicia, la Iglesia, la representación, la merced, las masas y la sociedad política de ambos países².

No en vano, los dos paradigmas citados han conseguido superar las viejas narrativas que hacían hincapié en la crisis y el declive socioeconómicos o en la guerra y el desorden político del período, de manera que casi renunciaban a encontrar claves reales y satisfactorias de comprensión y explicación a las considerables transformaciones políticas operadas entre los siglos XIII, XIV y XV. En dicho marco de renovación historiográfica es en el que hemos querido inserir el presente dossier sobre el desarrollo político europeo bajomedieval, con un especial énfasis en diversos reinos de la península Ibérica, como Aragón, Castilla, Navarra, Portugal y Valencia, pero con extensiones a otros territorios occidentales, como Irlanda, Escocia, Inglaterra y el Imperio Germánico. En concreto, los variados trabajos aquí incluidos giran de una manera o de otra en torno al proceso de progresiva politización de la sociedad claramente perceptible hacia el año 1200, que condujo a la ampliación de los actores políticos y a la búsqueda de soluciones negociables a los conflictos

2 FLETCHER, C., GENET, J. P. y WATTS, J., Government and Political Life in England and France, c. 1300-c. 1500, Cambridge, 2015. 
de todo tipo, llegando a situar las nociones de orden público y bien común en el centro de las relaciones sociales.

A dicho cambio primigenio dedica precisamente la profesora de la Universidad Complutense de Madrid Ana Carrasco su artículo, desde una perspectiva de la historia conceptual que sigue los pasos de Koselleck, Brunner o Guerreau, tratando de reconstruir el sentido del concepto de "política" durante el siglo XII, cuando el vocablo y sus derivados comienzan a multiplicarse, incluso antes de la recepción de La política de Aristóteles. Como observa, especialmente a través del análisis semántico del Policraticus de John of Salisbury (c. 1120-1180), fue entonces cuando, reinterpretando conceptos recuperados de autores clásicos como Cicerón, Agustín de Hipona o Macrobio, se fue gestando la noción de comunidad política o res publica, en estrecha conexión con las nuevas formas de gobierno, administración, justicia y juridificación que fueron apareciendo a partir de aquellas fechas. El proceso se intensificaría a partir del siglo XIII y, no en vano, también se multiplicarían las referencias a lo político y se ampliarían notablemente los actores sociales participantes en el conjunto de las relaciones políticas.

De ello habla la profesora de la Universidad Pública de Navarra Eloísa Ramírez para el caso concreto del reino navarro entre mediados del siglo XII y el primer tercio del XIV. Reflexionando sobre conceptos como "sociedad política", "opinión pública" y "pueblo" a partir de los planteamientos de autores como Raymond Cazelles y Claude Gauvard, repasa el proceso de ampliación de los interlocutores políticos con la realeza, desde la Curia regia de magnates laicos y eclesiásticos hasta las Cortes de 1329, que incluían representantes de la baja nobleza infanzona, de las villas francas y hasta del llamado "otro pueblo", haciendo referencia al resto de núcleos villanos, pequeños consejos de labradores que cobraban importancia política en un momento de cambio dinástico. Aunque a continuación desaparecieron para siempre del mapa de las grandes negociaciones del reino, su presencia es testimonio de la complejidad política y del proceso de ampliación de los elementos que adquirieron protagonismo político durante la baja edad media, tanto por arriba como por abajo de la escala social.

En dicho sentido, aquellas centurias fueron también el escenario de un considerable aumento de los cuadros de gobierno y administración de diversos ámbitos de poder, tanto a nivel de la Corona como de la Iglesia, los señoríos, los municipios o las regiones. En dicha evolución se produjeron al mismo tiempo fenómenos de protesta, exigencia, aceptación y controversia por parte de los sectores sociales afectados, lo que era, en definitiva, parte de un proceso mayor de legitimación o rechazo de dichas estructuras políticas 
en formación. Un buen ejemplo de ello en el campo de la acción regia de gobierno es el caso de los consejeros reales, aquí estudiados en la Corona de Aragón por parte de Alexandra Beauchamp, profesora de la Université de Limoges. Sin duda, más allá de la atención relativa que les prestaban las Ordinacions de la Casa i Cort encargadas por Pedro el Ceremonioso en 1344, su número e importancia fueron en aumento a lo largo de los siglos bajomedievales, en consonancia con el ensanchamiento de la sociedad política y el aumento de las competencias del poder real. Es por ello que, al mismo tiempo que su papel fue generalmente aceptado como uno de los elementos necesarios para ejercer el buen gobierno, también fueron objeto de mayor presión social y disputa, como muestran las protestas contra los "mals hòmens de Consell" que capitalizaron las Cortes Generales de Aragón, Cataluña, Mallorca y Valencia en 1383.

La ampliación y consolidación de los sistemas de gobierno también conllevó, pues, una mayor exigencia de transparencia, rectitud y comportamiento equitativo para los miembros de la sociedad política, como resultado del pacto social y el contrato tácito que unía a gobernantes y gobernados. En este sentido, la lucha por el cumplimiento de dicho contrato, para evitar los abusos y procurar el recto funcionamiento de las instituciones de justicia y gobierno, se convirtió en una constante a lo largo de los siglos posteriores, con soluciones diversas en función de los equilibrios de poder y las variadas evoluciones sociopolíticas. En Castilla, por ejemplo, el profesor de La Sorbonne François Foronda explica que la orientación contractual de su régimen político llegó a su apogeo en el tercer cuarto del siglo XV, impulsado por un conjunto de servidores medianos de la Corona y por las ciudades y villas reales. Así queda reflejado en una apelación al "contrato callado" existente entre el rey y el reino en las Cortes de 1469, que posteriormente sería reeditada en 1518, en vísperas de la revuelta de las Comunidades. Con todo, Foronda muestra aquí que, contrariamente a lo que se había planteado, dicha referencia no era una evolución de la ley de inalienabilidad del realengo "por pacçión e contracto" promulgada en 1442, sino que esta, por su contexto, sería una oferta monárquica de autolimitación graciosa de su poder, mientras que la de 1469, formulada por los procuradores urbanos, recogería, en cambio, el principio de soberanía popular extraído de la Lex Regia de Ulpiano.

El resultado de dicha pugna es conocido en el caso castellano, con la pérdida de poder de decisión política de las ciudades en el siglo XVI y el triunfo de la voluntad regia, escoltada por el gran poder nobiliario y eclesiástico. En cualquier caso, la emergencia del poder urbano y de las ciudades como actores políticos principales es, evidentemente, una de las características más 
notables del período bajomedieval. Así lo apunta el profesor de la Universidad de Zaragoza Mario Lafuente para el caso de Zaragoza, capital del Reino de Aragón. Desde su conquista y refundación cristiana en el año 1118, la ciudad fue claramente privilegiada por los monarcas, tanto a nivel fiscal y de aprovechamiento de los recursos naturales del territorio como en sus competencias jurisdiccionales, con el objetivo de aumentar su poder en alianza con la propia Corona. Lafuente muestra las estrategias llevadas a cabo por los gobernantes zaragozanos, que, generación tras generación, negociaron con otros poderes, especialmente con la realeza, para materializar, reproducir, concretar y ampliar dichos poderes. Además, junto a su emergencia política, hacia mediados del siglo XIV, en un proceso que recuerda en cierta manera al que hemos visto en Navarra y se observa en otras muchas partes de Europa, se produjo también un cambio hacia el cierre y la oligarquización de su poder, en este caso a través de la construcción de la categoría de los "ciudadanos honrados", que pasaron a ocupar las magistraturas municipales.

Dicha irrupción del poder urbano, y también sus límites ante otros poderes de ámbito territorial mayor, se observa con nitidez en zonas como el norte de Italia, dominado por las ciudades-estado, o en grandes partes del Imperio Germánico, donde la intervención directa de los emperadores se mantuvo alejada durante mucho tiempo. En ello se adentra el profesor del Messiah College de Pennsylvania Joseph Huffman, a través del ejemplo de las diversas ligas renanas de ciudades formadas entre los siglos XIII y XIV, con el objetivo de mantener el orden público, resolver conflictos con los prelados y barones regionales y desarrollar redes diplomáticas, comunicativas, militares y administrativas comunes en ausencia de una autoridad central fuerte. Ciudades como Colonia, Worms, Maguncia, Núremberg o Frankfurt recurrieron así a una de los mecanismos de asociación más generalizados de la época para coordinar grupos de pares con propósitos de autogobierno, resistencia o representación. Con todo, salvo algunas excepciones, como la Confederación Helvética, dichas ligas urbanas carecieron normalmente de permanencia y acabaron sucumbiendo ante el avance de estructuras superiores de poder centralizado.

En cambio, en otros territorios con un grado menor tanto de urbanización como de centralización fueron los magnates aristocráticos los que protagonizaron de manera principal las relaciones políticas. Así lo muestra el profesor de la University of St Andrews Michael Brown para el caso de dos zonas marginales del Reino de Escocia y el Señorío de Irlanda, los Grampians y la provincia de Munster. Ambas estuvieron gobernadas durante el siglo XIV por lugartenientes reales, del monarca escocés y el inglés respectivamente, 
pero los intereses de los grandes señoríos nobiliarios fueron los que vehicularon por completo su desarrollo político, con lógicas regionales apartadas de los núcleos centrales del poder en Glasgow, Londres o Dublín. Así, al tiempo que las luchas aristocráticas vertebraban la evolución política de aquellas regiones, la Corona tendió a delegar en los magnates la aplicación de la justicia, el mantenimiento del orden público y la recaudación de tributos. No obstante, a partir del siglo XV la mayor presencia de la monarquía escocesa en los Grampians, más cercana y constante que la inglesa en Munster, acabó por hacer más notoria en la zona la autoridad real, que continuaba mediatizada por los grandes nobles, pero ahora con una serie de obligaciones y servicios más definidos con respecto a la Corona.

Dicha participación y colaboración de la nobleza en la extensión del poder real centralizado es también destacada por el profesor de la Universidad de Salamanca José María Monsalvo para el caso de la Corona de Castilla en la zona suroccidental del río Duero. En concreto, entre los siglos XIV y XV los concejos de villa y tierra que se encontraban en torno a las urbes de Ciudad Rodrigo, Salamanca y Ávila pasaron a manos primero de los infantes de Aragón y más tarde de los Álvarez de Toledo, los Estúniga y los La Cueva, con el tiempo duques de Alba, Béjar y Alburquerque. De esa forma, manteniendo los principales núcleos urbanos reales, la monarquía era capaz, por una parte, de apaciguar las luchas nobiliarias mediante concesiones territoriales y jurisdiccionales y, por otra parte, de extender e intensificar su dominio centralizado, aunque lo hiciera compartiéndolo con la propia nobleza. De hecho, aquella cesión de poder y apoyo a determinados magnates nobiliarios acabaría conllevando la intromisión e influencia de estos en las relaciones políticas de las mencionadas ciudades reales.

Buena muestra de dicha participación de la nobleza en la expansión del poder real, al mismo tiempo que del suyo propio, la encontramos también en el Reino de Valencia, a través del enfrentamiento explicado por el director del Archivo de la Corona de Aragón, Carlos López, entre dos de las principales casas señoriales de la parte meridional del territorio durante la primera mitad del siglo XV, los Maça de Liçana y los Corella. Mientras que los primeros no supieron encontrar por entonces el favor regio y mantuvieron estancada su fortuna, aunque aun así ejercieron como gobernadores reales en la zona, los segundos protagonizaron un claro ascenso social vinculado a los servicios prestados a la monarquía, lo que les llevó a ocupar cargos de poder aún más importantes y a ampliar notablemente sus dominios y su prestigio hasta alcanzar el título de condes. En cualquier caso, ya fuera a través de la resistencia o de la colaboración con la Corona, ambas casas señoriales par- 
ticiparon del proceso de ensanchamiento y legitimación de las instituciones políticas regias y territoriales, dado que participaron activamente de ellas en su búsqueda por ampliar el poder propio.

Sobre dicha mezcla y difusa diferenciación entre las actuaciones privadas y públicas en la progresiva construcción de los organismos políticos de los estados centralizados reflexiona el investigador de la Universidade Nova de Lisboa Tiago Viúla de Faria, a partir del ejemplo, durante el segundo cuarto del siglo XV, de los asuntos diplomáticos negociados por Pedro de Avis, infante de Portugal, duque de Coimbra y regente del reino a lo largo de una década hasta su desplazamiento y posterior asesinato. En concreto, el desarrollo de una carrera diplomática realizada por media Europa en el nombre del rey de Portugal, pero con hombres procedentes de sus propias redes clientelares, e incluso con sus propias armas y símbolos heráldicos, apunta a dicha confusión entre los intereses aristocráticos y reales, que aún no se consideraban netamente públicos o con una lógica estatal moderna propia. Nuevamente, la colaboración e interacción entre diversos ámbitos de poder, atravesadas al mismo tiempo por el conflicto, formaba parte de la integración y el desarrollo protagonizado por los diversos territorios políticos bajomedievales.

Dicho desarrollo también fue acompañado, como ya se ha mencionado, por una progresiva formación y autoconsciencia de la opinión pública y del diálogo político en el ámbito de la comunicación social. Al expandirse los sistemas políticos y ensanchar la base de los miembros que participaban en ellos, tanto por la parte de los gobernantes como de los gobernados, también se amplió notablemente la intervención en los debates sobre el funcionamiento de las instituciones y el comportamiento de los que ocupaban cargos y puestos de poder. Lo documenta la profesora de la University of Oxford Helen Lacey para el caso de Inglaterra, donde ya a finales del siglo XIII se promulgaron leyes para evitar las calumnias contra los monarcas, magnates y grandes oficiales de la Corona, que se ampliaron posteriormente, a finales del XIV. Durante dicha centuria, además, documenta numerosos casos presentados ante los tribunales regios, que muestran la intervención de importantes partes de la población en las discusiones, tramas y estrategias que afectaban a la dirección de los asuntos políticos de la comunidad, conformando así una opinión pública más amplia de lo que se pudiera pensar o se ha estudiado hasta el momento.

No en vano, las campañas de desprestigio en forma de versos, canciones y carteles políticos llegaron a provocar el asesinato del duque de Suffolk, William de la Pole, en 1450, en nombre de la justicia popular, según expone Clementine Oliver, profesora de la California State University. La dimensión 
social de la política y de las guerras mantenidas por el conjunto de Inglaterra, en este caso en Normandía, era ya tan grande que sus dirigentes se vieron sometidos a toda una serie de presiones que exigían unos resultados adecuados a los intereses comunes del reino. Así pues, la opinión pública ya formaba parte de la cultura política del momento, en consonancia con el desarrollo de las instituciones colectivas de gobierno y administración que se puede observar a lo largo de la sociedad occidental, con diferentes ritmos en cada territorio y región, entre los siglos XIII y XV.

Son varios aspectos de dicho proceso general los que precisamente hemos tratado de mostrar en este dossier a través del ejemplo de diversas partes de Europa. Evidentemente, son muchos los países y también los asuntos relativos a todo ello que han quedado fuera, algunos tan importantes como, por ejemplo, el papel de la Iglesia o el desarrollo de la justicia, los ejércitos, la fiscalidad y las instituciones de representación y administración municipal y territorial. En cualquier caso, son una buena muestra de la vitalidad de una nueva historia política que ha sabido sumar las aportaciones realizadas desde otras ramas de la historiografía y que trata de superar, al mismo tiempo, las antiguas narrativas que veían con cierta incomprensión y extrañeza los sucesos y cambios políticos producidos durante el período bajomedieval, que no son tanto de caos y descomposición como de formación y desarrollo. 